\title{
INVESTIGATION OF TWO-PHASE LIQUID-METAL MAGNETOHYDRODYNAMIC POWER SYSTEMS
}

by

William E. Amend, Gracip Fabris and John Cutting

NOTICE

This report was prepared as an account of work sponsored by the United States Government. Neither the United States nor the United States Energy Research and Development Administration, nor any of their employees, nor any of their contractors, subcontractors, or their employees, makes any warranty, express or implied, or assumes any legal liabiiity or responsibility for the accuracy, completeness or usefulness of any information, apparatus, product or process disclosed, or represents that its use would not infringe privately owned rights.

For Presentation at:

International Seminar on Future Energy Conversion in Heat and Mass Transfer Problems

Dubrovnic, Yugosiavia, August 25-30, 1975 
INVESTIGATION OF TWO-PHASE LIQUID-METAL

MAGNETOHYDRODYNAMIC POWER SYSTEMS

WILLIAM E. AMEND*, GRACIO FABRIS*, AND JOHN CUTTING ${ }^{+}$

Argonne National Laboratory, Argonne, Illinois, U.S.A.

\section{ABSTRACT}

Magnetohydrodynamic power systems are receiving renewed interest as a result of the need to develop more efficient energy conversion systems. One of these systems, the two-phase Liquid-Metal MHD (LMHD) system, is under development at the Argonne National Laboratory. This paper presents the result of the detailed cycle analysis and systems studies, a description of the experimental facility and the basic results obtained, and the thermal and magneto fluid mechanics problems encountered in two-phase liquid-metal flows in the presence of a magnetic field.

Detailed cycle analysis and in-depth modeling studies have indicated that power cycles utilizing two-phase liquid metal MHD generators are attractive alternates to conventional power-generation techniques from the standpoint of coupling to available heat sources and to provide improved efficiency. The studies indicate that the LMMHD cycle will operate efficiently in the temperature range of $1000-1600^{\circ} \mathrm{F}\left(50 \%\right.$ efficiency with a maximum cycle temperature of $1600^{\circ} \mathrm{F}$ ) and is therefore potentially compatible with many advanced heat sources under development such as the LMFBR, fluidized-bed coal combustor, HTGCR and the fusion reactor. Of special interest is the coupling to the LMFBR thereby eliminating the costly, potentially hazardous liquid-metal/water interface.

The results of detailed parametric studies of the heat transfer interfaces between an LMMHD power cycle and an LMFBR and a steam bottoming plant are described. It is shown that the interfaces do place restrictions on the possible range of operating parameters but that a viable systern can be designed to couple with an LMFBR operating with a maximum coolant temperature at $1200^{\circ} \mathrm{F}$ to yield an overall conversion efficiency approaching $45 \%$.

Results of the cycle studies and thermodynamic analysis show that the twophase generator approaches the operation of an infinite reheat turbine and is responsible for the high cycle efficiencies. It is also indicated that the generator is the only unique, umproven component of the system and must operate at an isentropic efficiency in excess of $70 \%$ for acceptable cycle performance.

Experimental evaiuatici or the two-phase LMHD generator has been performed in an ambient tcm, $C=$ ature $2 a \mathrm{~L}-\mathrm{N}_{2}$ facility at AN. Results of these experiments, performed to determine the operating characteristics of the device as a function of the various independent parameters and to investigate two-phase

* Argonne National Laborator $j$, Argonne, Illinois

+ STD Research Corporation, Arcadia, California 
electrically conducting flows in a magnetic field, have shown that the three major loss mechanisms in the LMHD generator; end losses, internal current shunting and slip losses, can be controlled to levels consistent with the acinievement of a generator efficiency in excess of $70 \%$. To date, the maximum measured generator efficiency is $55 \%$ and the analytical models of the generator indicate that scaling up to larger, more practical designs should yield the required improvement in performance.

\section{INTRODUCTION}

LIquid Metal Magnetohydrodynamic (LMHiD) power systems have been developed as a means of obtaining the requisite electrical conductivity of 10 mhos/m for MHD power production without encountering the extremely high temperatures $\left(3000-4000^{\circ} \mathrm{K}\right)$ required for open-cycle seeded-gas MHD systems. Since pure liquid metals have electrical conductivities in excess of $10^{\circ}$ mhos/m (four orders of magnitude higher than for open cycle plasmas) for temperature in the range of 100 to $1000^{\circ} \mathrm{K}$, it is not necessary to increase the temperature of the liquid metal to reach the conductivity threshold. Thus LMMD powe ystems are essentially low temperature devices whose range of operating temperatures are determined by the thermodynamic and physical properties of the fluids.

Liquid Metal Magnetohydrodynamic energy-conversion systems were originally conceived in the early $1960^{\prime} \mathrm{s}$ as compact power systems for space and other special applications [1]. Thus, the LMMHD concepts studied in the early stages of development operated in limited parameter ranges not attractive for commercial applications [2]. Subsequent systems studies with sophisticated mathematical models of two-phase LMMHD power systems identified a basic power cycle that appeared to be attractive for central station power generation with maximum cycle temperatures in the range of $1000-2000^{\circ} \mathrm{F}[3,4,5]$.

A variety of advanced heat sources currently under development in this country are projected to supply heat in this range of temperatures and the attractiveness of the two-phase liquid metal MHD power cycle is enhanced by its potential compatibility with most of these sources. For example, the liquidmetal fast breeder reactor (LMFBR), the fusion reactor and the high temperature gas cooled reactor (HTGCR) are projected to operate between $1000^{\circ} \mathrm{F}$ and $1800^{\circ} \mathrm{F}$. In addition, the fluidized bed combustor being developed to provide "clean" thermal energy from high-sulfur coal will have a top temperature in the 1400$1600^{\circ} \mathrm{F}$ range. It has also been shown that LMMHD cycle can also be used as a bottoming cycle with a plasma MHD topping unit [6].

Steam cycles, the only established, commercially vaible present technology system, operate with an upper temperature 1 imit below $1100^{\circ} \mathrm{F}$, which 1 imit its efficlency to about $40 \%$. Of added importance, the liquid-metal water interface in the liquid-metal-cooled reactors may create severe interfacing problems. Therefore, a liquid-metal MHD power cycle would have an obvious advantage in coupling to these reactors. Other characteristics possessed by the LMMHD system that make it attractive for centrai stations power plants are: a) simple coupling to the various heat sources; b) considerable promise of improved reliability since there are no hot highly-stiessed moving parts to be cooled; c) the MHD generator, a geometrically simple device with no moving parts, performs the functions of both turbine and electrical generator (both of which are relatively expersive to build naintain); d) a Brayton-type cycle operation that means dry cooling terers could be incorporated economically into the system, and e) competitive or high performance potential at a given temperature.

This paper presents the status of the program at Argonne National Laboratory to develop the two-phase LIMHD power system. In the first sections 
the basic cycle under consideration is presented, the cycle performance is discussed, and the problems of coupling to an LMFBR are considered.

In the following section the experimental program to provide the basic understanding of the two-phase flow in a magnetic field and demonstration of the generator performance is presented.

\section{Cycle Description}

LMMD power systems require two-phase fluids in the primary system loop to allow sufficient energy extraction to take place in the MHD generator. The liquid phase, whose primary purpose is to provide the required electrical conductivity, is termed the electrodynamic fluid. The gaseous phase, whose main purpose is to 'drive' the liquid through the generator during the expansion process, is called the working fluid. The electrodynamic fluid also increases the effective specific heat of the two-phase mixture, thus acting as a heat source for the working fluid and causing the two-phase LMMD generator to emulate an infinte-reheat turbine in its operation.

The two-phase LMMP generator can be used in several types of power cycles. These cycles can be classified as Rankine, Brayton or supercritical cycles depending upon the choice of the combinations of working and electrodynamic fluids and system operating conditions. All three types of cycles appear to have potential. application for central station power generation. However, the Rankine and supercritical cycles are still under investigation and the knowledge of the potential of these systems is incomplete and thus will not be considered here.

There exist many possible configurations of the Brayton-type LMMD cycle. An extensive study was done to evaluate the possibilities and one cycle configuration emerged as having much potential merit for efficient power generation in central stations. This cycle, shown schematically in Fig. 1, has been studied in depth to evaluate its performance limits. An inert gas is used as the thermodynamic working fluid and a liquid metal as the electrical conductor (i.e. electrodynamic fluid). In operation, the gas and liquid are mixed, and the mixture enters the generator where the expansion of the gas drives the conducting liquid across the magnetic field and generates electrical power. The two phases are separated and both are returned to the mixer, each through a separate loop. The gas phase passes through a regenerative heat exchanger, a reject heat exchanger, is compressed in a multistage compressor, and then returns via the regenerative heat exchanger and the heat source to the mixer. The liquid is rectrculated back to the mixer via the heat source by means of a nozzle-diffuser system. Note that heat can be added to the gas, the liquid, or both simultaneously.

Positive features of the cycle include the following: 1) because of the relatively high mass flow ratio of liquid to gas, and the fact that heat is transferred to the gas from the liquid metal during the expansion, the expansion proceeds almost isothermally; 2 ) the regenerative heat exchanger recoups a major fraction of the energy in the gas (the gas is still at essentially the high temperature of the mixer); and 3) multistage compression with interstage cooling can reduce the temperature rise and make the compression approach an isothermal process. The combination of these three features make the ideal cycle approach a Carnct $: \cdots$, lence, it has the potential for high efficiency. other important advali..... . iciuic: i) heat rejection begins at relatively high temperature and tive is no vanor to condense, allowing the effective use of dry-cooling towers; and 5) the cycle can be matched to various temperature ranges by selection of the working fluid combinations and independent parameter values. The major disadvantage of the cycle is that, as in ali Brayton cycles, 
the compression work represents a substantial fraction of the gross energy produced, which means that the cycle efficiency is very sensitive to the component performance.

Variations of the basic cycle are possible, and they may produce improved performance. Replacing the nczzle-separator-diffusor system for recirculation of the liquid by a pump tends to improve performance and allows greater freedom of selection of the working fluids. A significant improvement in cycle performance is achieved by using a gas turbine to drive the compressor, as shown in Fig. 2. This is a dual cycle with a double expansion of the gas, first through the MHD generator, and then through the turbine.

Perhaps the most important near-term application for the two-phase LMMD power system is as an energy-conversion device for the LMFBR. The schematic of a binary cycle that employs the dual IMMHD system as a topping cycle on a conventional steam plant and eliminates the water-liquid metal interface with an LMFBR is shown in Fig. 3. Detailed analysis indicates that these cycles have excellent performance potential, as will be discussed.

\section{Cycle Evaluation}

Extensive analysis of the various two-phase cycles has been and is continuing to be carried out $[3,4,5,6]$. Detailed mathematical models have been developed for all major components of the cycle and incorporated into a computer simulation of the LMMHD system. All known major loss mechanisms have been included in the models. All of the components in the cycle except the generator are essentially, standard "off the shelf" components used in present-day power systems and are simulated by lumped parameter representation with assumed efficiencies. The generator efficiency is not assumed--it is calculated using a mathematical model developed from experimental studies. The efficiency used to characterize cycle performance is defined as the net power output divided by the rate of heat addition in the primary heat exchanger.

Several principal factors strongly affect performance. These are:

1) the variation of the gas to liquid velocity as the two-phase mixture expands through the generator; 2) the variation of the electrical conductivity with the volumetric void fraction (defined as the ration of the iross-sectional area occupied by gas to the total cross-sectional area of the channe1) and hence the expansion ratio; 3 ) the generator load voltage and the aspect ratio limitations; and 4) the compressor, diffuser, and heat exchanger efficiencies. The experimental program currently underway is oriented toward resolving questicnable factors. In all the cycle studies, to maintain a common basis, the ratio of gas to liquid velocity has been taken to be unity, throughout the extent of the generator. The void fraction at the exit of the generator has been limited to $a_{0}=0.85$ since at higher void fractions the electrodynamic working is no longer a continuum. It has also been assumed that the end losses can be reduced by $80 \%$ when compared to the end losses that can be calculated for an abrupt termination of the magnetic field [7].

The calculated performance of the basic cycle as a function of mixer temperature TMIX and exit void fraction $\alpha_{0}$ for lithium and helium is shown in Fig. 4. The performance would be similar for other fluid combinations. At the higher exit void fractions (expansion ratios) the efficiency is becoming competitive $r i$ the steam cycle $n 14: \cdots$ axceds it as the tempurature is increased.

Significant increases in projected efficiencies are achieved with the inclusion of a gas turbine in the cycle as shown in Fig. 5. The comressor may 
be driven by the turbine or by the MHD generator, whichever yield the best performance. The projected cycle efficiency of above 0.40 at $1200^{\circ} \mathrm{F}$ is comparable with that of the steam cycle. Significant increases are posfible at higher temperatures, and an overall efficiency of 0.50 appears realizable at $1600^{\circ} \mathrm{F}$.

Two potentially serious problems for the application of the steam cycle with the LMFBR are the water-1iquid metal interface and the relatively low cycle performance projected for the system $(<40 \%)$. The use of the two-phase LMMHD system as a topping cycle has the potential to circumvent both problems. However, the heat-transfer interfaces of the LMMHD energy-conversion system with the LMFBR and with the bottoming steam cycle place restrictive constraints on the combined-cycle operating perameters. The viable system configurations are limited by the values of the interfacing heat-transfer parameters such as temperatures and fluid-flow rates, while the coupling configurations place certain constraints on the range of operating parameters of the energy-conversion system.

The system configuration that was found to have the greatest potential to interface with the LMFBR is shown in Fig. 3. The temperature of the LMFBR coo1ant exiting the reactor was selected at $1660^{\circ} \mathrm{R}$ while the minimum value of the water entering the feedwater heater was set at $550^{\circ} \mathrm{R}$. The most severe constraint on the binary plant operating parameters are imposed by the interface between the two cycles. Iypical helium and water temperatures in the feedwater heater and boiler are plotted in Fig. 6 as a function of location. The 1imiting parameter is the pinch point $\mathrm{PP} 2=\mathrm{T}_{\mathrm{cr}}-\mathrm{T}_{\mathrm{st}}$, since $\mathrm{PP} 2$ is always less than PP1 or PP 3 when operating under the vapor dome. Figure 7 shows the variation of PP2 as a function of the steam boiler pressure for various values of superheat temperatures. Physically meaningful sclutions (i.e. PP2 > 0) are seen to exist only as the boiler pressure approaches the critical value (because the latent heat of vaporization of water goes to zero as the pressure approaches the critical value) and only for maximum steam temperatures significantly below the temperature of the helium entering the boiler (i.e. PP1 $>200^{\circ} \mathrm{F}$ ). It is also important to note that as $\mathrm{T}_{40}$ decreases, more severe restrictions will be placed on the existence of solutions.

Other independent interface parameters studied included $T_{w}$, the temperature of the feedwater entering the heater and $T_{7}$, the temperature of the helium exiting the boiler (entering the compressor). The results of varying these two parameters can be sumarized as follows:

1. The restriction on PP1 can be relieved somewhat by going to large values of $\mathrm{T} 7$, but only at the expense of reduced topping cycle performance.

2. It is desirable to operate with $T_{W}$ as low as possible to relieve the interface constraints somewhat and to ensure that the efficiency of the bottoming plant will be high.

As a result of the parametric study of the LMHD/Steam interface, the operating point of the MHD generator was selected to be:

$\begin{aligned} \mathrm{T}_{\operatorname{mix}} & =1560^{\circ} \mathrm{R} \\ \mathrm{P}_{\operatorname{mix}} & =1000 \text { psia } \\ \alpha_{1} & =0.75 \\ \cdot \alpha_{0} & =0.85\end{aligned}$


The UMHD cycle code was run for these generator conditions to yield $\mathrm{T}_{40}=1542^{\circ} \mathrm{R}$ and from the parametric study of the LMMHD/Steam interface, $T_{S t}=1242^{\circ} \mathrm{R}$ (i.e. PP1 $=300^{\circ} \mathrm{F}$ ), $\mathrm{P}_{\mathrm{St}}=3000$ psia was selected as the operating point for the steam bottoming plant. The value of PP 2 for this operating point was calculated to be $20^{\circ} \mathrm{F}$ which is deemed acceptable ty engineering standards.

The interface between the LMFBR and the LMMD cycle is not nearly so restrictive since the splitting of the reactor-coolant flow into two heat exchangers provides much flexibility as shown in Fig. 8. A solution exists (1.e. PP3 $>0$ ) for all values of $\overline{\mathrm{PP} 1}$ in the range of 0 to $100^{\circ} \mathrm{F}$ (note that $\overline{\mathrm{PP} 3}$ and $\overline{\mathrm{PP} 4}$ are essentially independent of $\overline{\mathrm{PP} 2}$ since the ratio $\mathrm{m}_{\mathrm{cl}} / \mathrm{m}_{\ell}$ is essentially independent of $\overline{\mathrm{PP} 2}$ over the range of interest). The operating point for the LMFBR/LMMHD interface was selected from Fig. 8 as follows:

$\overline{\text { PP1 }}=\mathrm{TH1}-\mathrm{T} 1=20^{\circ} \mathrm{F}$
$\overline{\text { PP2 }}=\mathrm{TC2}-\mathrm{T} 9=20^{\circ} \mathrm{F}$
$\overline{\mathrm{PP} 3}=59^{\circ} \mathrm{F}$
$\overline{\mathrm{PP4}}=\mathrm{T} 1-\mathrm{T} 5=104^{\circ} \mathrm{F}$
$\mathrm{m}_{\mathrm{c} 1}=24086 \mathrm{lb} / \mathrm{sec}$
$\mathrm{m}_{\mathrm{c} 2}=7531 \mathrm{~b} / \mathrm{bec}$

This information corbined with that developed above yields the power-plant configuration whose state points are shown in the schematic in Fig. 3 . This plant is calculated to have an overall efficiency of $44.8 \%$ which compares favorably with the values in the mid to high $30 \%$ range currently being quoted for LMFBR's coupled to modern steam plants.

An attractive variation is the all-MHD binary cycle using a coal-fired plasma MHD generator operating on combustion gases as the topping cycle, a two-phase liquid-metal MHD dual cycle with a gas turbine as the bottoming cycle, and a heat-recovery steam cycle with an efficiency of 0.29 [6]. The potential match is good--the full rejection temperature of the plasma system may be used, and the helium for the bottoming cycle can cool the plasma generator. This cycle operating at the present state-of-the-art (TMIX $=1200^{\circ} \mathrm{F}$ ) is predicted to have a maximum efficiency of 0.51 , which is about $6 \%$ higher than the plasma MHD-steam system projection of 0.481 obtained under the same conditions in the plasma cycle and with an 0.40 efficient steam bottoming cycle. As highertemperature materials become available, the efficiency will improve, reaching 0.55 at $T_{M I X}=1600^{\circ} \mathrm{F}$. The performance predictions depend on the effectiveness of the heat exchangers from combustion gas to air and to liquid metal, and the values used are felt to be reasonable. Performance predictions by others for the plasma MHD/Steam system of 0.488 to 0.497 for similar conditions appear to justify the model and conclusions [8].

\section{Experimental Program}

In the cycles described in the previous section the only new, unproven component in the liquid-metal loop is the two-phase liquid-metal MHD generator. Therefore, research has been concentrated on this device in an effort to: 1) determine generator performance characteristics as a function of the primary independent $\because \because$ tem variables, ara $\because \quad \therefore \quad \cdots$ in a basic understanding of two-

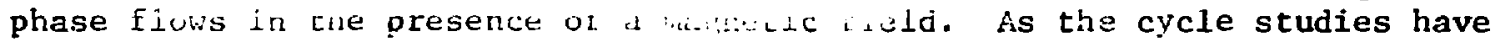
indicatcd the neressity for the $\delta .: \cdots$. or to operate at an isentropic effictciency of greater than $70 \%$, a substantial effort has been directed toward controlling the principle loss mechanisms inherent in the generator. These loss mechanisms; 
end losses, internal-leakage currents [13], and losses due to the relative velocity between phases (slip)and the experimental methods used to control them are discussed in this section.

In addition to demonstrating high efficiency for the generator it 1 s also necessary to evaluate operation at temperatures approaching realistic cycle temperatures. A program of the experimental evaluation of a sodiun-argon generator at $1000^{\circ} \mathrm{F}$ is in progress at ANL.

Experiments have been performed on the ambient temperature $\mathrm{NaK}-\mathrm{N}_{2}$ facility described in detail in Reference 9. Basically this facility is a MHD ${ }^{2}$ low loop capable of Independently variable flow and fleld conditions as indicated below:

$\begin{array}{lr}\text { NaK Flow Rate } & 7.0 \mathrm{Kg} / \mathrm{sec} \text { max. } \\ \mathrm{N}_{2} \text { Flow Rate } & 0.1 \mathrm{Kg} / \mathrm{sec} \text { max. } \\ \text { Generator Entrance Pressure } & 26.5 \mathrm{bar} \\ \text { Magnetic Field Strength } & 0.6-1.2 \mathrm{Tes} 1 \mathrm{a} \\ \text { Load Resistance } & 0.1 \mathrm{~m} \Omega-2.0 \mathrm{~m} \Omega ; \infty\end{array}$

The loop and generator are instrumented to provide diagnostic information at critical points in the generator and end regions. The measurements include pressures, temperatures, void-fractions and voltage profiles as well as mass flow rate. The void fraction results are used to determine phase velocity of the gas and liquid. Details of the data handling are described in Reference 10.

The generator is of rectangular cross section with continuous copper electrodes and fiberglass insulating side walls. The side walls are interchangeable so that both constant and variable area channels may be tested with minimum experimental difficulty. Typical dimensions and operating parameters are:

$\begin{array}{ll}\text { Channel Length } & 0.385 \mathrm{~m} \\ \text { Channel Height } & 0.1 \mathrm{~m} \\ \text { Entrance Width } & 0.014 \mathrm{~m} \\ \text { Exit width (variable) } & 0.014-0.025 \mathrm{~m} \\ \text { Mixture Velocity } & 12 \mathrm{~m} / \mathrm{sec} \\ \text { Power Output } & 2-3 \mathrm{kn} \\ \text { Turbine Efficiency } & 50-55 \%\end{array}$

Extensive experimental studies have indicated that the primary loss mechanisms in the generator can be controlled by proper design and operation. End losses can be reduced by providing magnetic field overhang. Reduction in end losses of over $80 \%$ of the value existent if the magnetic field terminates abruptly at the ends of the electrodes has been demonstrated with proper field shaping. Therefore, end-current losses will not significantly affect generator performance.

Isentropic efficiency of $76 \%$ has been demonstrated [7] with a liquid-metal single-phase MHD generator with aspect ratio (ratio between length of generator and distance bewecil electrocis: aly four. 'It is certain that higher efficiencies are anievable wi $:$ : -1, le-phase generators of larger aspect ratios or when insulating vanes are usid in cnd regions.

Internal ohmic losses in the generator occur when the velocity decreases in the conducting fluid buundary layer. This phenomena is especially important 
In the two-phase generator when the core conductivity may be significantly lower than the conductivity at the walls due to bubble migration toward the channel centerline. Internal shunt currents have been greatly reduced ty boundary-layer control along the insulating side walls of the generator. It was analytically and experimentally determined that the highly conducting, slowmoving liquid boundary layer along the insulator wall was acting as an internal current shunt [11]. Consequently the turbine efficiency of the generator was significantly less than predicted at the high void fraction necessary for efficient cycle performance. This loss is aggravated by the tendency of the bubbles to migrate to the center of the channel, thereby increasing the ratio of boundary layer to core conductivity.

Effective displacement of ci.e conducting boundary layer, and a resulting improvement of generator performance has been accomplished by injecting a thin $(0.3 \mathrm{~mm}) \mathrm{film}$ of $\mathrm{N}_{2}$ along the insulator wall at three axial locations in the generator [12]. An indication of the improvement in performance is shown in Fig. 9. The data with gas injection shows an improvemenc in efficiency of almost $50 \%$ over data obtained without gas injection at the lower load resistance. Also the data obtained with gas injertion agrees much more closely with the theory. Similar resulis were also obtained for open-circuit runs where the voltage was observed to increase from 1.35 volts to 1.80 volts when the bas injection was utilized. With gas injection, the maximum neasured turbine effictency is $55 \%$ with a mixture quality of 0.005 and $B=1.2 \mathrm{~T}$. Since an efficlency of this level was obtain in a subscale device with a non-optimum aspect ratio (channel length/height) it is likely that full-scale generatcrs with greater than $70 \%$ efficiency can be constructed.

Efficient generator performance is dependent upon reduction of the slip velocity between phases to less than about 1.5. Although the goal of near unity slip is difficult to achieve at the high void fractions $(0.65-0.80)$ required for optimum cycle performance, experiments have show that slip may be controlled by proper selection of the generator independent variables such as velocity anc magnetic-field strength. Typical experimental results for maximum slip ratio in a slightly diverging channel are shown in Fig. 10 for a mixture quality of 0.01 . The maximum slip ratio decreased for almost three to two when the 1+quid flow rate (i.e. velocity) was increased from two to six $\mathrm{kg} / \mathrm{sec}$ at a magnetic field strength of $1.2 \mathrm{~T}$. When the magnetic field strength was reduced to $0.6 \mathrm{~T}$ a similar change in liquid flow rates resulted in a slip decrease from about 2.2 to 1.5 .

\section{Future Work}

As shown, increasing liquid flow rate and decreasing the magnetic fleld strength reduces the slip ratio and will yield a generator with increased efficiency. Subsequent experiments are planned at $A N$ at velocities cf 15-30 m/sec and low $B$ fields where effects of slip should be minimized.

Research has also been initiated on surface activity in liquid metals [14]. If proper surface ective additives to liquid metal are found, coalescence of gas bubbles at high qualities would be greatly impeded and foam-like flow could be generated. This in turn would virtually eliminate slip loss, increase electrical conductivity of the mixture and perhaps make possible operation at void fraction above 85\%. Optimization of bourdar.-1 nyer control is also being considered.

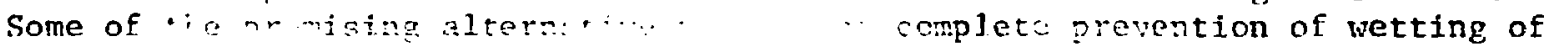
insulato: valls by liquid metai ar: . . in iection through forous walls, electromagnetic repulsion of liquid-metal boundary layers and film boiling of liquid metal. 
In addition to ambient temperature experiments, a program is currently uncerway to test a mixer-generatcr-separator system at $1000^{\circ} \mathrm{F}$. This prograil is being carried out on an existing high-temperature sodium facility at ANL. The facility is presently being modifled to accept the MHD components. The loop is capable of a sodium $f$ low of $800 \mathrm{gpm}$ and argon will be used as the thermodynamic working fluid in these experiments. Results of the experiments should document the high-temperature performance of the two-phase 11quid-metal MHD generator and, if successful, provide sufficient information for the design and construction of a high-temperature pijot plant.

Thermodynamical analysis of a Rankine cycle is currently underway. Preliminary results incicate further improvement in overall cycle efficiency.

\section{Summary}

Cycle studies show that the two-phase liquid-metal MHD power cycle has excellent potential for an advanced energy-conversion system in central station power generation. The advantages of the LMAHD are: 1) effective coupling to fossil heat sources such as fluidized-bed combustors or to liquid-metal-cooled heat sources such as the breeder or fusion reactor, 2) elimination of the liquidmetal-to-water interface in liquid-metal-cooled reactors, and 3) improved cycle performance at limiting steam temperatures and the potential to operate at elevated temperature.

Detailed analysis of the heat transfer interfaces between the LIFBR and a LMMHO/Steam binary cycle indicates that although the interfaces do restrict the operational range of the "independent" cycle parameters it is possible to find operating points consistent with efficient cycle performance. The thermodynamic anaiysis of one example was presented which projected that a LMFBR operating with a maximum coolant temperature of $1200^{\circ} \mathrm{F}$ coupled to a LMHD/Steam energy-conversion system will have an overall cycle efficiency of $44.8 \%$.

Experimental results indicate that the loss mechanisms associated with the LMMID generators can be controlled. Isentropic generator efficiencies in excess of $55 \%$ have been measured on a subscale device and performance extrapolation to a larger, more efficient design indicates that actual performance can exceed the critical value required for efficient cycle operation.

A high-temperature generator testing program has begun that, if successful, should lead to development of a pilot plant. Operational information with sodium and argon at $1000^{\circ} \mathrm{F}$ will be obtained and associated naterials experience will supplement the materials investigations underway in connection with the breeder and rusion reactor programs.

In view of the high potential of the LMMHD cycles and demonstrated performance of the most critical component, the concept warrants additional resejrch and development support and serious consideration as an emerging energy-conversion system for the future energy requirements.

\section{References}

1. M. Petrick, "Recent nerelomments in Liquid-Metal MHD Power Syste:",

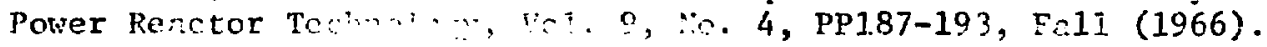

2. W. E. Amend, M. Petrick and E. S. Pierson, "Liquid-Metal MHD for Central Stations", Proc. of American Power Conference, Chicago, I11. May 8-10, 1973. 
3. W. E. Amend, C. Hsu, M. Petrick and J. Roberts, "Performance of a QuasiEricson Two-Phase Two-Component Liquid-Netal MHD Power Cycle", Proc. of 11th Symp. on Engineering Aspects of MHD, Cal. Tech., Pasadena, Calif. April (1970).

4. W. E. Amend, M. Petrick and J. C. Cutting, "Analyses of Liquid-Metal MHD Power Cycles for Central Station Power Generation", Proc. of 12th Symp. on Engineering Aspects of MHD, Argonne, I11., March (19/2).

5. W. E. Amend and M. Petrick, "Performance of an Efficient Low-Temperature Liquid-Metal MHD Power Cycle", Proc. of 5th International Conference on MDD Electrical Power Generation, Munich, Afril (1971).

6. J. C. Cutting and W. E. Anend, "Evaluation of a Plasma/Liquid Metal MHD Cycle for a Central Station Power Plant", Proc. of 13 th Symp. on Engineering Aspects of MHD, Stanford, Calif., April (1973).

7. M. Petrick, J. J. Roberts, G. Lambert and E. Spleha, "Analytical and Experimental Studies of Single- and Two-Phase Liquid-Metal Faraday Generators, Generators", Report No. AFAPL-TR-58-93, Wright-Patterson AFB, Ohio August (1968).

8. P. D. Bergman, K. D. Plants, J. J. Demeter and D. Bienstock, "An Appraisa1 of Coal Gasification Schemes for IHD Power Generation", Proc. of 12th Symp. on Engineering Aspects of MHD, Argonne, Ill. April (1972).

9. L. C. Pittenger, "Experimental Two-Phase Liquid-Metal Magnetohydrodynamic Generator Program", ANL-72-07, Argonne National Laboratory, June (1972).

10. L. C. Pittenger, W. E. Amend, R. Cole and E. S. Pierson, "Experimental Studies of Constant Velocity Two-Phase Liquid-Meta1 MHD Generator", Proc. of the 13th Symp. on Engineering Aspects of MHD, Stanford University, Stanford, Calif., April (1972).

11. W. E. Amend, R. Cole and J. C. Cutting, "The Effects of Geometry and Loss Mechanisms on the Performance of Two-Phase Liquid-Yetal MHD Generators", Proc. of the 14th Symp. on Engineering Aspects of MHD, University of Tennessee Space Institute, Tullahoma, Tenn., April (1974).

12. J. C. Cutting, R. Cole and W. E. Amend, "Boundary Layer Coratrol in TwoPhase Liquid Metal MHD Generators", Proc. of the 14th Symp. on Engineering Aspects of MHD, University of Tennessee Space Institute Tullahoma, Tenn., April (1974).

13. B. G. Iotkovskii and V. V. Kirillov, "Effect of Boundary Layers on the Electrical Characteristics of MHD Generators", Teplofirika Vysokikh Temperature, V. 6, No. 4, Pp. 558-594, 1968.

14. P. Kozakevitch, "Surface Activity in Liquid Metal Solutions", Society of Chemical Industry, London 1968. 

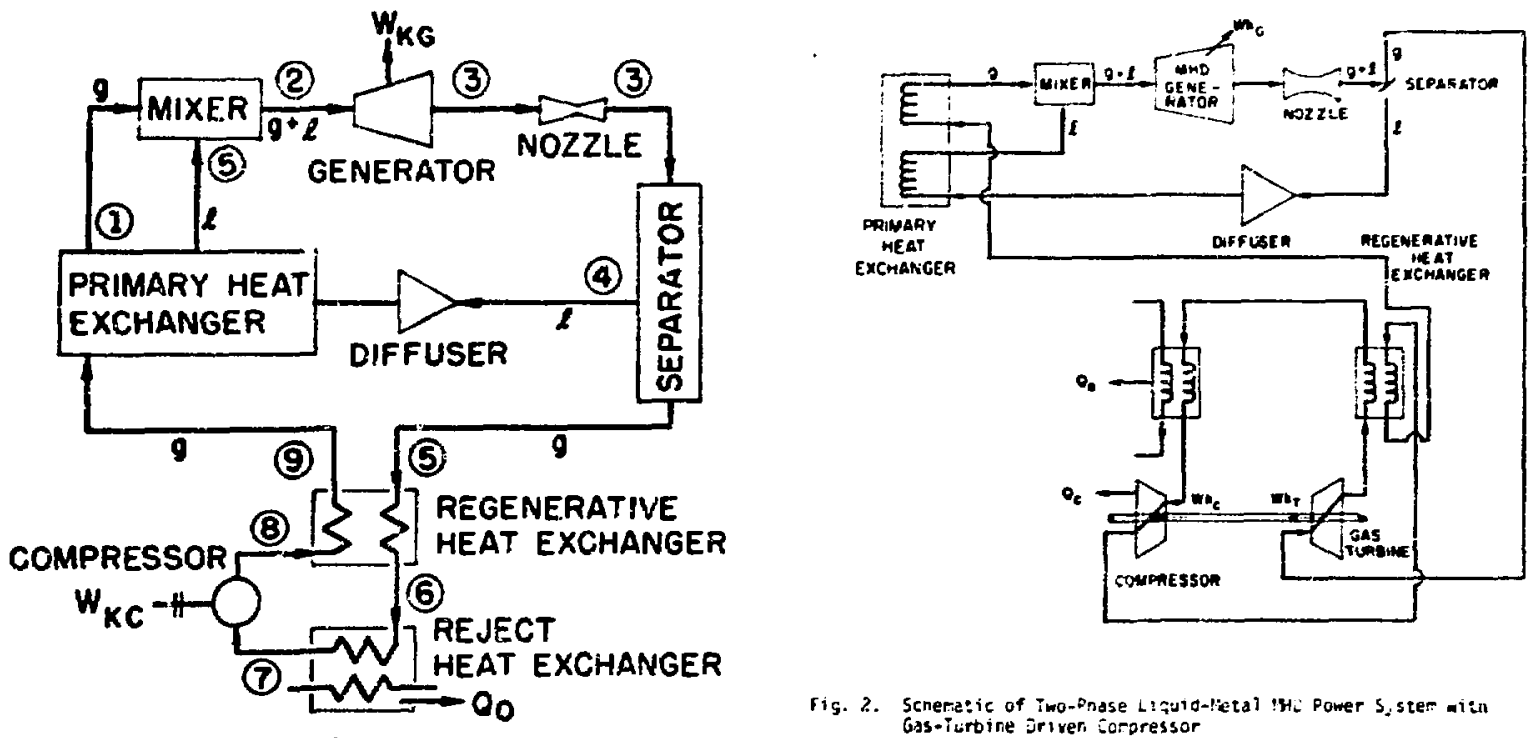

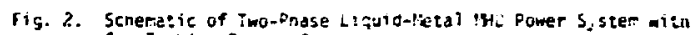
Gas-icitine jriver Sorpressor

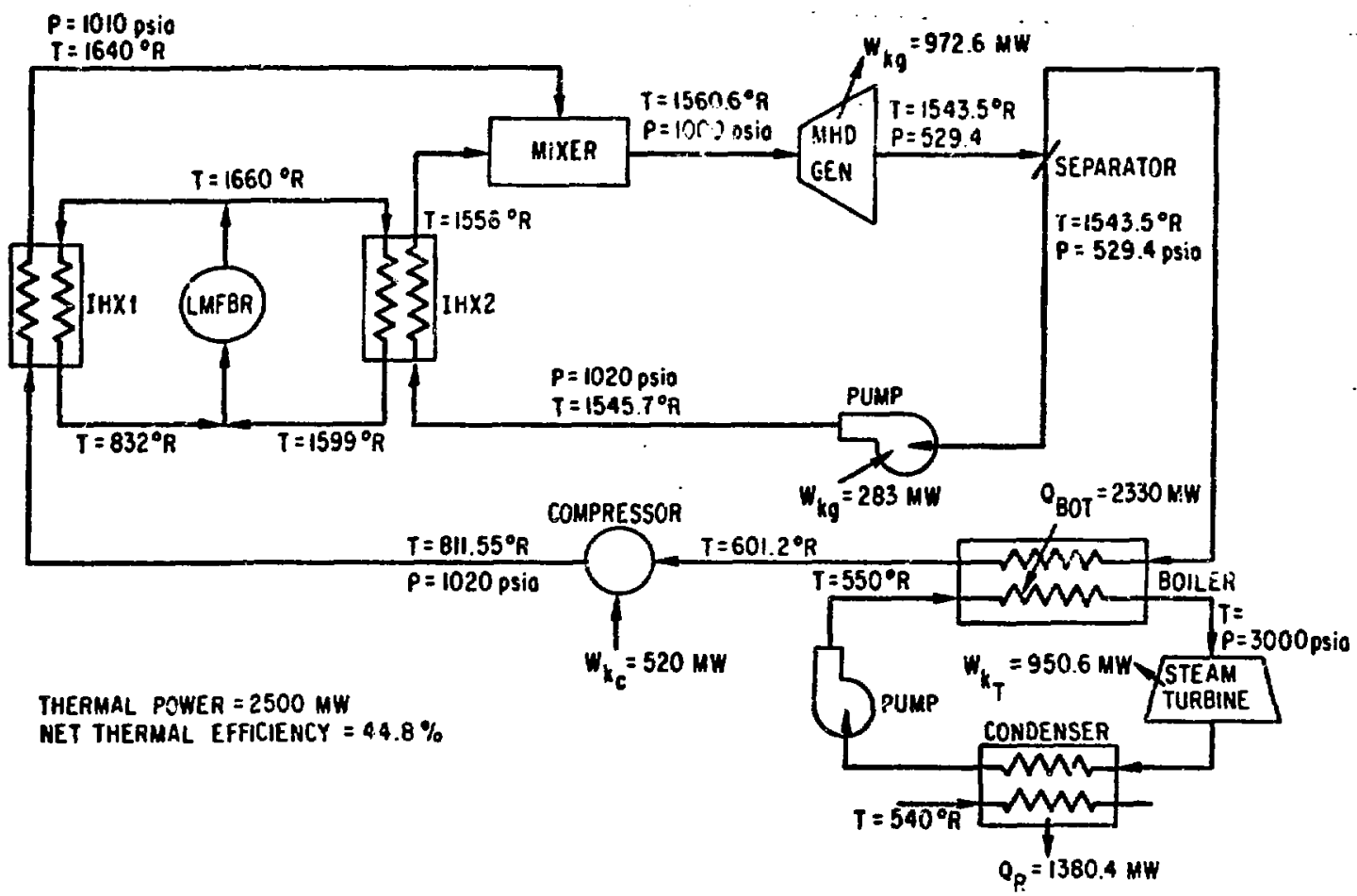

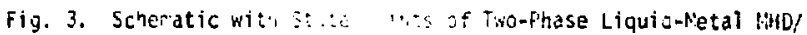
Steam Binary runot ugiti, litertaced with LiFB: 


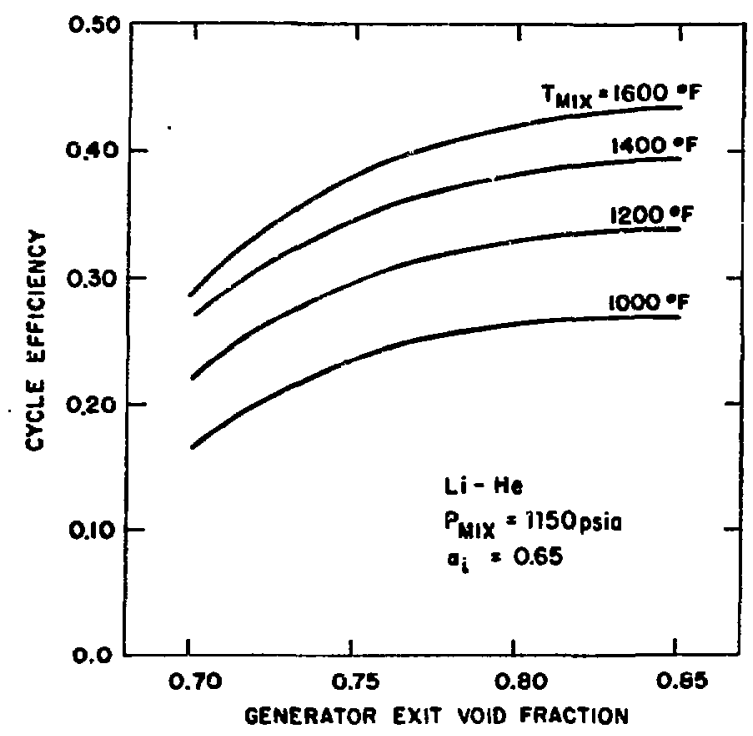

Fig. 4. Perfomance Curves for Basic Two-Phase Liquid-itetal BHU Power System
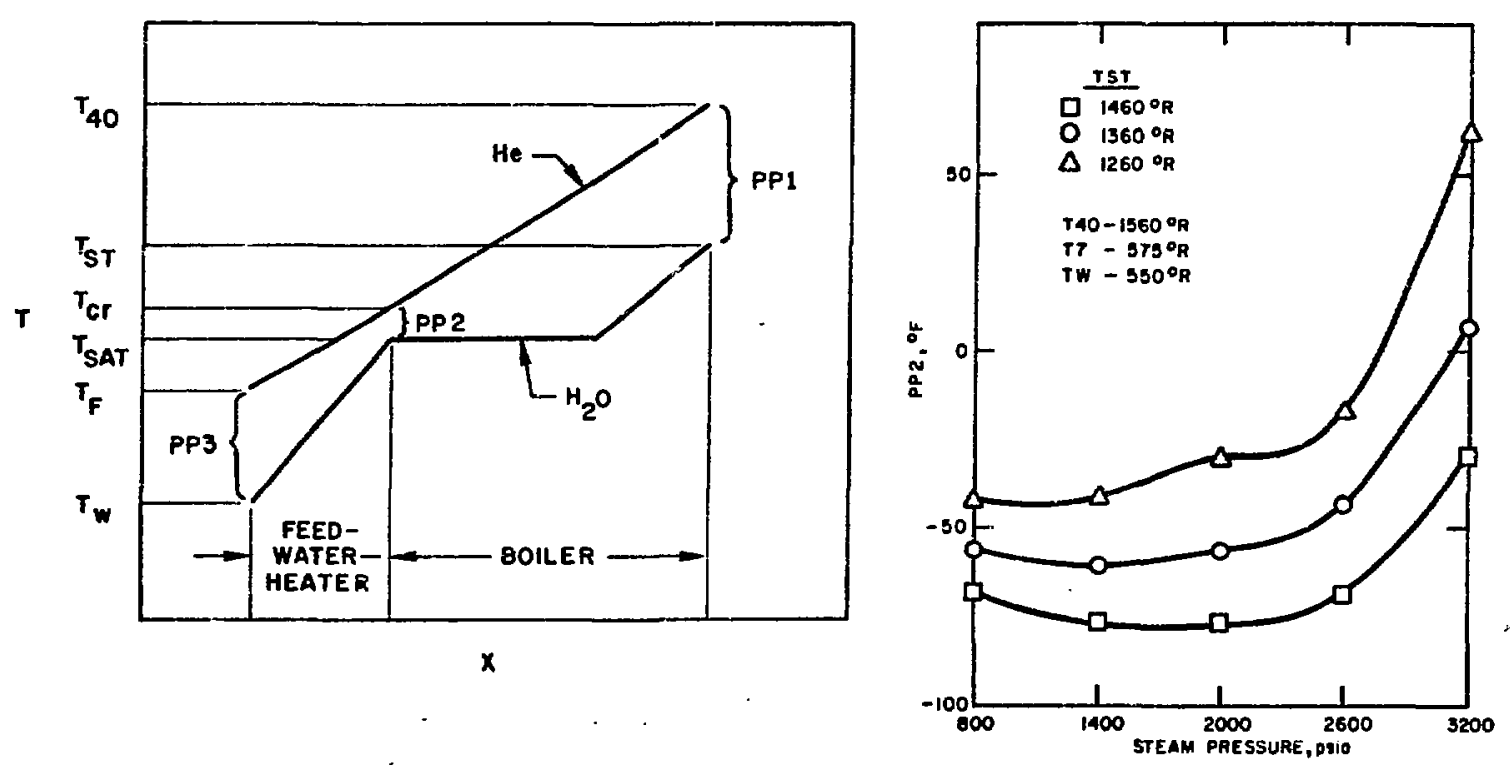

Fig. 6. Fypical Cirves of Terperature vs. Incation in Feed-iater meater and Bailer

Fig. 7. Curves of PP2 vs. Stean pressure in Boiler for Various Steam Superheat Temperatures 

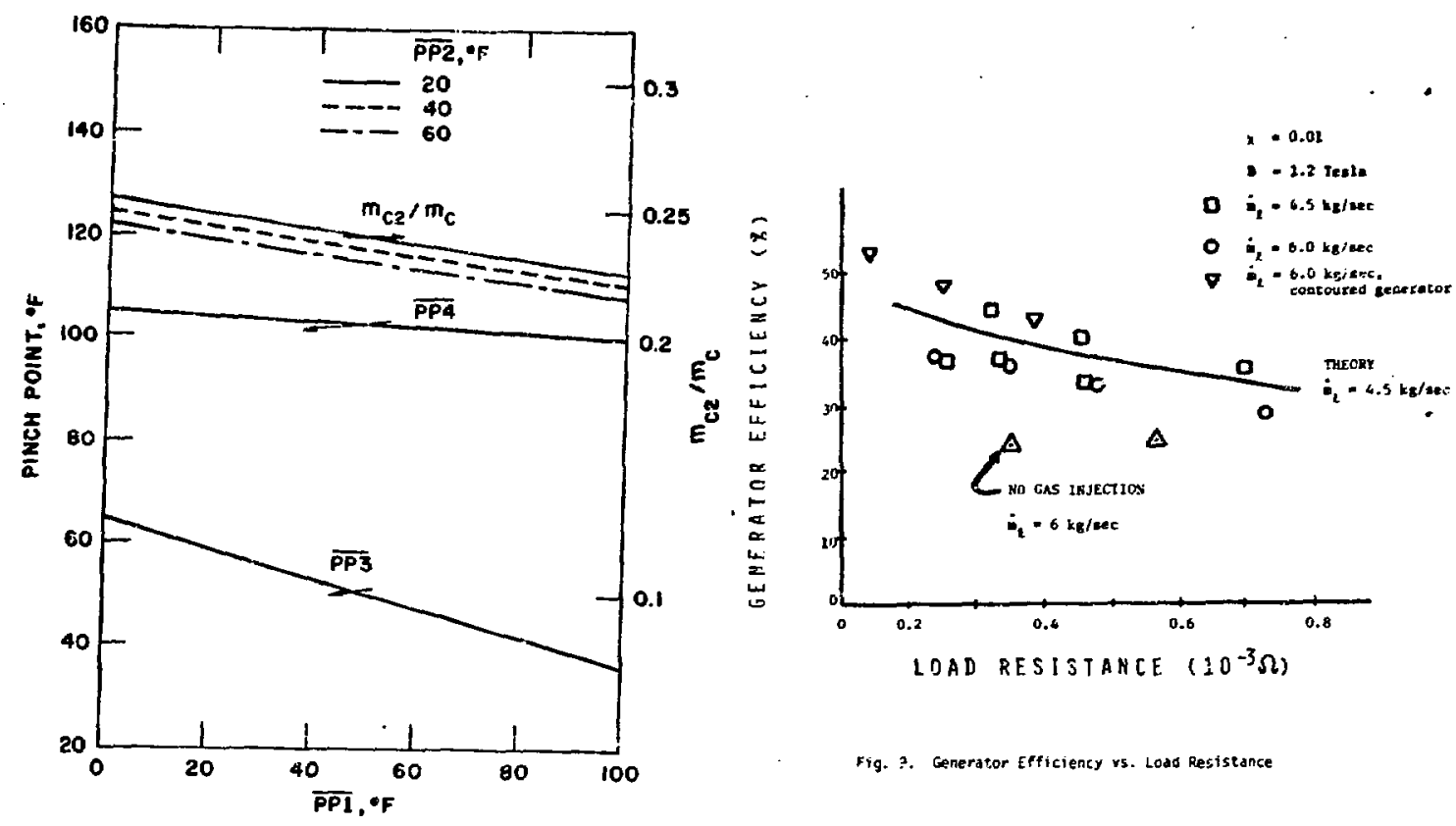

F1g. A. Poranetric Curves of the LHWO/Steam Interface

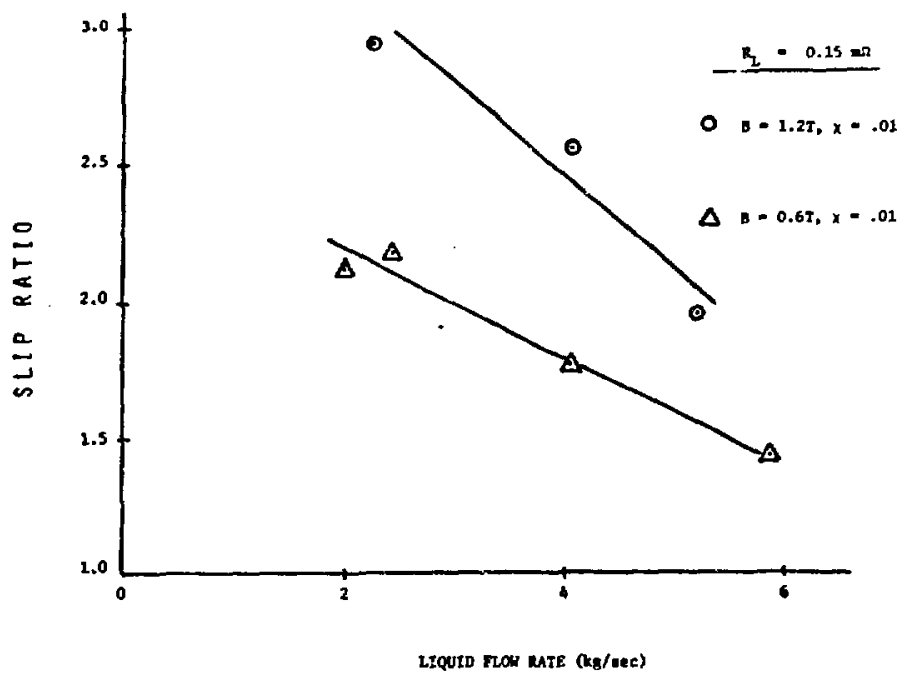

fig. 10. Slip Ratio vs. Liquld Flow Rate 